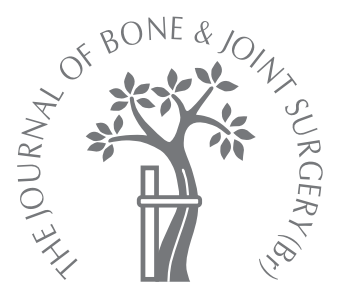

M. Al-Rashid, K. Theivendran, M. A. C. Craigen

From Selly Oak Hospital, Birmingham, England

\title{
Delayed ruptures of the extensor tendon secondary to the use of volar locking compression plates for distal radial fractures
}

The use of volar locking compression plates for the treatment of fractures of the distal radius is becoming increasingly popular because of the stable biomechanical construct, less soft-tissue disturbance and early mobilisation of the wrist. A few studies have reported complications such as rupture of flexor tendons. We describe three cases of rupture of extensor tendons after the use of volar locking compression plates. We recommend extreme care when drilling and placing the distal radial screws to prevent damaging the extensor tendons.

One of the aims of the design of volar locking compression plates for the treatment of fractures of the distal radius is the avoidance of complications with the dorsal soft tissues sometimes associated with dorsal plating. ${ }^{1}$ These complications include tendonitis and tendon rupture and can occur in $12 \%$ to $23 \%$ of cases. ${ }^{2-6}$ Several recent studies have supported the use of volar locking compression plates for fixation in osteoporotic and comminuted bone, allowing early active movement. ${ }^{1,3,7-9}$ Rozental and Blazar ${ }^{10}$ described 41 patients, all of whom achieved either good or excellent results as judged by the Gartland and Werley $^{11}$ scoring system. Two required removal of the plate, one for irritation of flexor tendons and the other for dorsal swelling and discomfort. Drobetz and Kutscha-Lissberg ${ }^{3}$ noted rupture of the tendon of flexor pollicis longus in $12 \%$ of cases after fixation with a volar plate. Other studies have described irritation and rupture of flexor tendons secondary to the use of volar plates. ${ }^{3,12,13}$ Extensor tendon injuries associated with the use of volar plates and volar locking plates are uncommon, although they can occur in undisplaced fractures treated conservatively. ${ }^{14}$ We describe three cases of rupture of the extensor tendon after treatment of displaced fractures of the distal radius by volar locking plates.

\section{Patients and Methods}

We retrospectively reviewed 35 patients with fractures of the distal radius who had been treated using volar locking plates (AO, Davos, Switzerland) between 2002 and 2004. All had complex displaced intra-articular fractures, 20 with both dorsal and 15 with volar angulation. There were 18 men and 17 women with a mean age of 51 years (31 to 88 ).

\section{Results}

Three patients $(8.6 \%)$ subsequently presented with a rupture of an extensor tendon, two involving extensor pollicis longus at four and 16 weeks, and one of extensor digitorum communis to the index finger and the tendon of extensor indicis proprius. There were no causes associated with the ruptures other than the application of the volar plates and screws.

The first of these patients was a 64 -year-old woman who sustained a displaced intraarticular fracture of the distal radius after a fall. Two days later she underwent open reduction and internal fixation with a $3.5 \mathrm{~mm} \mathrm{~T}$ shaped AO locking compression plate $(\mathrm{AO})$ applied to the volar aspect. Four weeks after surgery her wrist was not painful; she had dorsiflexion of $40^{\circ}$, palmar flexion of $40^{\circ}$ and full supination and pronation. However, she reported that she was unable to extend her thumb. Radiography showed that the fracture was healing in a satisfactory position (Fig. 1). She underwent exploration of the extensor compartment which revealed a rupture of the extensor pollicis longus tendon with no evidence of protrusion of screws. However, an empty drill hole made at the time of initial surgery was found at the base of the third dorsal compartment. The tendon injury was treated by an extensor indicis proprius to extensor pollicis longus tendon transfer with a satisfactory result. 


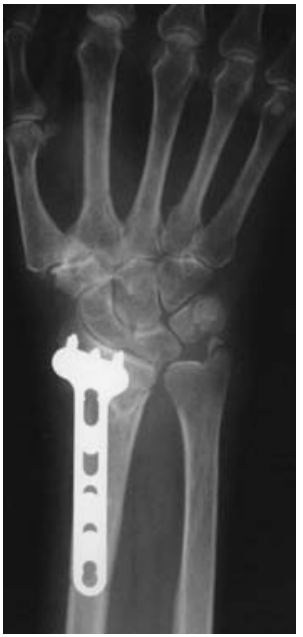

Fig. 1a

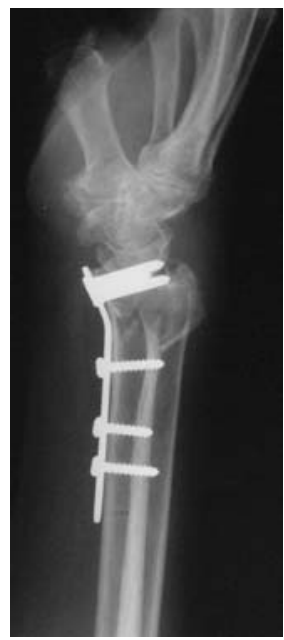

Fig. 1b
Case 1. a) Anteroposterior and b) lateral radiographs showing the volar locking plate in position, and healing of the fracture.

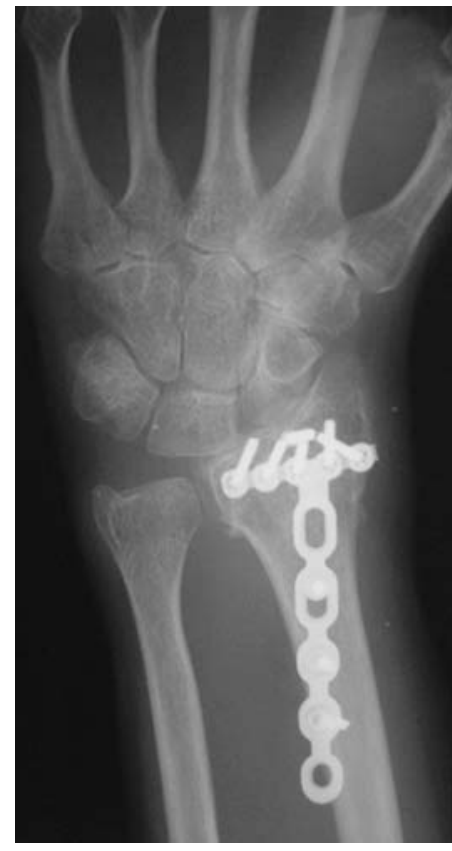

Fig. 2a

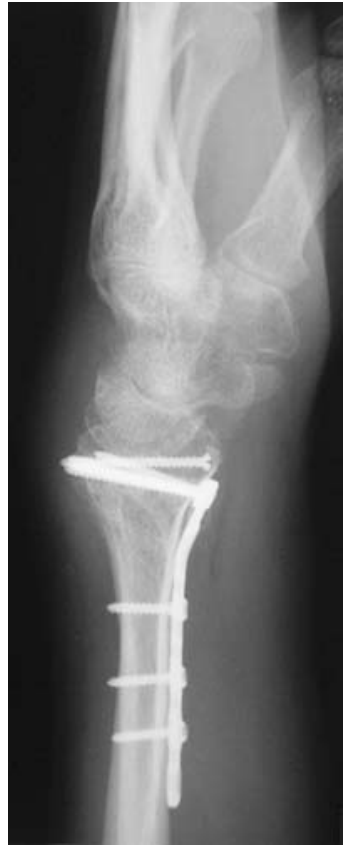

Fig. $2 b$
Case 2. a) Anteroposterior and b) lateral radiographs showing fixation.

In the second case, a 50-year-old right-handed man fell from his bicycle, landing on his left outstretched hand. He sustained a comminuted displaced intra-articular fracture of the left distal radius with volar angulation. He underwent open reduction and internal fixation with an AO titanium volar $\mathrm{T}$ plate (AO) with five screws (Fig. 2). Postoperatively, he achieved full supination and pronation with

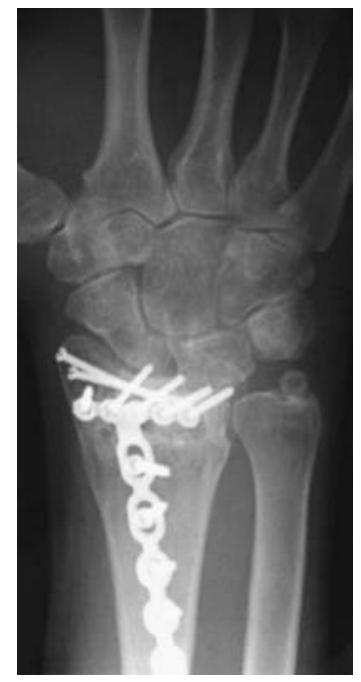

Fig. 3a

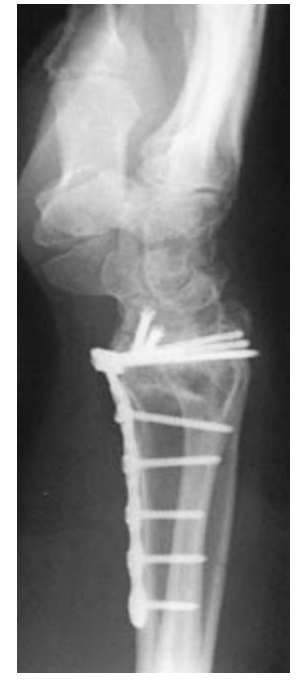

Fig. 3b
Case 3. a) Anteroposterior and b) lateral radiographs showing fixation.

$40^{\circ}$ of dorsiflexion and palmar flexion. However, four months later he was unable to extend the interphalangeal joint of his left thumb. He subsequently underwent removal of the plate and was found to have a rupture of the extensor pollicis longus tendon with a screw hole found in the third compartment. The rupture was due to attrition on the screw. He had an extensor indicis proprius to extensor pollicis longus tendon transfer with a good result.

The final case was a 40-year-old right-handed man who sustained a comminuted intra-articular fracture of the right distal radius with volar angulation. He underwent fixation using an $\mathrm{AO}$ titanium volar locking plate (AO). Fixation of the radial styloid was achieved by a combination of lag screws and buttress pins (Fig. 3). He made an unremarkable recovery. One year later he became unable to extend his right index finger and was found to have a complete rupture of the extensor digitorum communis tendon to the index finger and of the extensor indicis proprius tendon. At exploration a screw was found to be protruding in the third compartment on the radial side near the tendon. He underwent removal of the plate and transfer of the extensor digitorum comminus tendon of the middle finger to the extensor digitorum comminus tendon of the index finger.

\section{Discussion}

Local irritation or rupture of an extensor tendon is a serious complication of the treatment of fractures of the distal radius. Fixation by a volar plate is attractive because of the direct restoration of the anatomy of the joint, stable internal fixation, a decreased period of immobilisation, and early return of wrist function. ${ }^{15}$

A previous series described a rate of rupture of an extensor tendon of $4.4 \%$ with the use of volar locking plates. ${ }^{16}$ 
We had an incidence of $8.6 \%$ after fixation using a volar locking plate for both dorsally and volarly angulated fractures of the distal radius. There were no other complications. In case 1, damage from drilling at the time of surgery was probably the cause of rupture of the tendon. The postoperative radiographs and subsequent surgical exploration revealed no evidence of protrusion of screws, which was probably the cause of the rupture in the second and third cases. It is possible that rupture could have occurred for reasons other than iatrogenic damage or attrition on protruding screws. However, the incidence of rupture of the extensor pollicis longus tendon after fractures of the distal radius treated conservatively is low $(0.07 \%$ to $0.88 \%) .{ }^{17,18}$ A study by Hove ${ }^{19}$ showed that in a period of five years, $0.3 \%$ of cases had rupture of the extensor pollicis longus tendon after such a fracture. It is suggested that ruptures of the extensor pollicis longus can occur after minimallydisplaced fractures because the attachment of extensor retinaculum to Lister's tubercle remains intact and together with formation of callus, leads to narrowing of the third compartment. ${ }^{20}$ This can cause reduction in the blood supply to the tendon, degenerative necrosis and eventual rupture. ${ }^{14}$ We recommend careful drilling and placement of the distal radial screws so that they sit flush on the dorsal cortex to prevent such complications. Another option is the use of a smooth pin although this may affect the ability to hold the reduction. Leaving the screws a little short is not desirable because engagement of the dorsal cortex allows compression of dorsal intra-articular fragments, preventing gapping or intra-articular steps.

\section{Supplementary Material}

$\ddot{e}$ A further opinion by Mrs Sue Fullilove is available with the electronic version of this article on our website at www.jbjs.org.uk

No benefits in any form have been received or will be received from a commercial party related directly or indirectly to the subject of this article.

\section{References}

1. Orbay JL, Fernandez DL. Volar fixation for dorsally displaced fractures of the distal radius: a preliminary report. J Hand Surg [Am] 2002;27:205-15
2. Kambouroglou GK, Axelrod TS. Complications of the AO/ASIF titanium distal radius plate system (pi plate) in internal fixation of the distal radius: a brief report. $J$ Hand Surg [Am] 1998;23:737-41.

3. Drobetz H, Kutscha-Lissberg E. Osteosynthesis of distal radial fractures with a volar locking screw plate system. Int Orthop 2003;27:1-6.

4. Lowry KJ, Gainor BJ, Hoskins JS. Extensor tendon rupture secondary to the A0/ ASIF titanium distal radius plate without associated plate failure: a case report. Am J Orthop 2000;29:789-91.

5. Campbell DA. Open reduction and internal fixation of intra articular and unstable fractures of the distal radius using the A0 distal radius plate. J Hand Surg [Br] 2000;25:528-34.

6. Schnur DP, Chang B. Extensor tendon rupture after internal fixation of a distal radius fracture using a dorsally placed A0/ASIF titanium pi plate. Ann Plast Surg 2000;44:564-6

7. Liporace FA, Gupta S, Jeong GK, et al. A biomechanical comparison of a dorsal $3.5-\mathrm{mm}$ T-plate and a volar fixed-angle plate in a model of dorsally unstable distal radius fractures. J Orthop Trauma 2005;19:187-91.

8. Osada D, Fujita S, Tamai K, et al. Biomechanics in uniaxial compression of three distal radius volar plates. J Hand Surg [Am] 2004;29:446-51.

9. Osada D, Viegas SF, Shah MA, Morris RP, Patterson RM. Comparison of different distal radius dorsal and volar fracture fixation plates: a biomechanical study. $J$ Hand Surg [Am] 2003;28:94-104.

10. Rozental TD, Blazar PE. Functional outcome and complications after volar plating for dorsally displaced, unstable fractures of the distal radius. J Hand Surg [Am] 2006;31:359-65.

11. Gartland JJ Jr, Werley CW. Evaluation of healed Colles' fractures. J Bone Joint Surg [Am] 1951;33-A:895-902.

12. Nunley JA, Rowan PR. Delayed rupture of the flexor pollicis longus tendon after inappropriate placement of the pi plate on the volar surface of the distal radius. $J$ Hand Surg [Am] 1999;24:1279-80.

13. Bell JS, Wollstein R, Citron ND. Rupture of flexor pollicis longus tendon: a complication of volar plating of the distal radius. J Bone Joint Surg [Br] 1998;80-B:225-6.

14. Hirasawa Y, Katsumi Y, Akiyoshi T, Tamai K, Tokioka T. Clinical and microangiographic studies on rupture of the E.P.L. tendon after distal radial fractures. J Hand Surg [Br] 1990;15:51-7.

15. Nana AD, Joshi A, Lichtman DM. Plating of the distal radius. J Am Acad Orthop Surg 2005;13:159-71

16. Zwetkow AN, Schibli SI, Canova MA, Mark GI, Sommer CH. Rupture of the extensor tendons: a complication following volar locking compression plate osteosynthesis of the distal radius. British Journal of Surgery 2005;92:900-18.

17. Cooney WP 3rd, Dobyns JH, Linscheid RL. Complications of Colles' fractures. J Bone Joint Surg [Am] 1980;62-A:613-19.

18. Lidstrom A. Fractures of the distal end of the radius: a clinical and statistical study of end results. Acta Orthop Scand 1959;41:1-118.

19. Hove LM. Delayed rupture of the thumb extensor tendon: a 5-year study of 18 consecutive cases. Acta Orthop Scand 1994;65:199-203.

20. Helal B, Chen SC, Iwegbu G. Rupture of the extensor pollicis longus tendon in undisplaced Colles' type of fracture. Hand 1982:14:41-7. 